Case Report

\title{
A Case Report on Mephentermine Induced Psychosis with Acute Liver \& Kidney Injury
}

\author{
Manjulika Debnath', Dipesh Bhagabati
}

${ }^{1}$ Resident, ${ }^{2}$ Professor and Head, Deparment of Psychiatry, Agartala Govt. Medical College and GBPH Hospital, Agartala, Tripura, India.

DOI: https://doi.org/10.24321/2454.8642.202102

I $\quad \mathbf{N} \quad \mathbf{F} \quad \mathbf{O}$

\author{
Corresponding Author: \\ Manjulika Debnath, Deparment of Psychiatry, \\ Agartala Govt. Medical College and GBPH \\ Hospital, Agartala, Tripura, India. \\ E-mail Id: \\ manjulika.03@gmail.com \\ Orcid Id: \\ https://orcid.org/0000-0002-3400-2157 \\ How to cite this article: \\ Debnath M, Bhagabati D. A Case Report on \\ Mephentermine Induced Psychosis with Acute \\ Liver \& Kidney Injury. Rec Adv Path Lab Med. \\ 2021;7(1\&2):4-6. \\ Date of Submission: 2021-04-25 \\ Date of Acceptance: 2021-06-13
}

\section{$\begin{array}{llllllll}\mathbf{A} & \mathbf{B} & \mathbf{S} & \mathbf{T} & \mathbf{R} & \mathbf{A} & \mathbf{C} & \mathbf{T}\end{array}$}

Background: Mephentermine is a sympathomimetic agent derived from methamphetamine. It is a commonly used drug for the treatment of hypotension during anaesthesia. Its abuse has markedly increased especially in the young population due to its stimulant properties and ability to boost performance in competitive sports or bodybuilding. Very few cases of Mephentermine dependence with or without psychosis have been reported from India and worldwide.

Case Description: A 24-year-old male presented with a sudden onset of behavioural abnormalities a few hours following the use of Mephentermine. He was very agitated and restless. On physical examination, tachycardia, elevated BP and bilaterally dilated pupils were found. His symptoms remitted within a few hours of using Injection Haloperidol $10 \mathrm{mg}$ with Lorazepam $4 \mathrm{mg}$ once. He was found to have grossly deranged liver and kidney function tests. There was no past and family history of any psychiatric illness. No past history of any physical illness.

Conclusion: No previous report of mephentermine induced psychosis with acute kidney and liver injury has been reported in the literature. Cases such as this may be common among the general public. Long term follow-up is required to know the course and outcome in such unusual cases.

Keywords: Mephentermine, Psychosis, Kidney, Liver Injury

\section{Introduction}

Mephentermine is $\mathrm{N}, \alpha, \alpha$-trimethylphenethyl amine sulfate dehydrate. It is structurally similar to methamphetamine. It is available as an oral tablet and IM or IV injection. The onset of action is prompt (within 5 to 15 mins) and the duration of action lasts up to 4 hours after IM injection. It is used as a vasopressor agent with sympathomimetic action, primarily causing the release of noradrenaline and increasing cardiac output. It has euphorigenic and relaxing effects.
The injectable preparation is indicated for the shortterm treatment of various hypotensive states, like shock accompanying $\mathrm{MI}$ or other severe medical illnesses, spinal anaesthesia or surgical procedures. Like amphetamines, it has also been shown to increase athletic performance in strength exercises and endurance in a dose of $14 \mathrm{mg} / 70$ $\mathrm{kg}$ body weight. Mephentermine is a stimulant whose use is prohibited by the World Anti-Doping Agency (WADA). ${ }^{6}$

Very few cases of Mephentermine dependence with or without psychosis have been reported from India and 
worldwide. Young people are misusing this substance for the purpose of better physical performance in competitive sports or bodybuilding. This current report is about a young male who used Mephentermine injection for better athletic performance during an army selection event and developed acute psychosis with acute liver and kidney injury.

\section{Case Report}

A 24-year-old male presented with sudden onset of behavioural abnormalities 5 hours following intravenous use of Mephentermine to boost his athletic performance. During the event, he could run for $5 \mathrm{kms}$ while many of his fellow participants gave up midway. But after running for $5 \mathrm{kms}$, he suddenly started to behave abnormally. He became very agitated and extremely restless. He started talking irrelevantly. He physically assaulted the selection personnel and bit the Medical Officer with the army when brought for a physical check-up. So he was brought by the Army for treatment at the Psychiatry Ward.

On his arrival at the Psychiatry OPD, he was in a very irritable mood. He was brought physically restrained but was still screaming and he could not be controlled by 5-6 strong Army men. He was extremely aggressive and did not answer any of the questions by the interviewer. On physical examination, tachycardia of $140 \mathrm{bpm}$, elevated BP of 150/90 mm $\mathrm{mg}$ and bilaterally dilated pupils were found. He was sweating profusely. Some prick marks were found on his forearms. His symptoms remitted within a few hours of giving Injection Haloperidol $10 \mathrm{mg}$ with Lorazepam 4 mg once.

On awakening after 4 hours, he was oriented to time, place and person. His mental status examination revealed no delusions or hallucinations and he was euthymic. Initially, he denied having used any substance but he later confided to having used Injection Mephentermine intravenously in the morning before his performance to increase his stamina. He did not reveal the amount he used. He denied having used it before so dependence could not be established. He claimed to have heard about this substance and its ability to boost performance from his friends at the gym. Despite having no previous physical illness and no clinical signs and symptoms, he was found to have grossly deranged liver function tests (S.bilirubin of $5.1 \mathrm{mg} / \mathrm{dl}$ and SGPT of 760 IU/L and SGOT of $930 \mathrm{IU} / \mathrm{L}$ ) and mildly deranged kidney function tests (S. urea of $68 \mathrm{mg} / \mathrm{dl}$ and S.creatinine of 2.5 $\mathrm{mg} / \mathrm{dl})$. There was clinically no icterus or organomegaly. Physician consultation was sought and they transferred him to medicine for the treatment of his acute liver and kidney injury. His behaviour was under observation for the next 7 days, but he showed no abnormal behaviour and there was no discrepancy in any of his areas of functioning henceforth. He received no psychotropic medication during this period.
There was no past history or family history of any psychiatric illness or any physical illness. There was no H/O epilepsy. No history of any other substance abuse. He was premorbidly well adjusted. He was discharged from the Medicine department as a case of Acute and Transient Psychotic Disorder (Mephentermine Induced) with Acute Liver Injury with Compensatory Acute Kidney Injury.

\section{Discussion}

There are few cases of mephentermine misuse or dependence reported in the literature. Basu \& Nebhinani (2009) reported a case of intravenous mephentermine dependence without any psychotic features. ${ }^{3}$ Similarly, De Sousa et al. (2010) reported a case of mephentermine dependence without psychotic features at a dose of 120 $180 \mathrm{mg}$ once or twice a week. ${ }^{5}$ Mephentermine acts at monoaminergic synapses and causes the release of monoamines (noradrenaline, dopamine and serotonin) in the brain. It undergoes demethylation to form amphetamine, which is an indirectly acting sympathomimetic CNS stimulant and a potent releaser of dopamine and noradrenaline. ${ }^{6}$ This is the probable reason for psychosis seen in mephentermine dependence. The euphorigenic and stimulant action of amphetamines on the brain make it a liable substance for abuse and dependence. Mephentermine in large doses may produce CNS stimulation with symptoms like anxiety, drowsiness, incoherence, hallucinations and convulsions. The misuse of Mephentermine can bring about major clinical implications like secondary hypertension and cardiovascular diseases such as arrhythmias and sudden death syndrome, ${ }^{7}$ but liver and kidney-related complications from mephentermine use along with acute and transient psychotic features as seen in this report have not been documented to date.

\section{Conclusion}

The abuse of mephentermine among the youth is becoming more rampant because of its use in bodybuilding and increasing stamina, though it is not frequently reported. Cases such as this may be common among the general public. Establishing public health programs to disseminate information about the risks involved to both users and nonusers, \& to provide specific treatment to already dependent patients would be beneficial. To know course and outcome in such unusual cases, studies with long term follow-up are required. Interventions in the form of drug monitoring programs and public health policies would be beneficial in the long run.

\section{Source of Funding: None Conflict of Interest: None References}

1. Singh P, Sidhu BS, Raj R, Mittal N. Mephentermine 
dependence: emerging trend of substance abuse and its challenges. Int J Med Dent Sci. 2019;8(1):1715-7. [Google Scholar]

2. Sawant NS, Vispute CD. Mephentermine dependence with induced psychosis. German J Psychiatry. 2012;15(2):69-71. [Google Scholar]

3. Basu $D$, Nebhinani N. Mephentermine dependence without psychosis. Indian J Med Sci. 2009 Mar;63(3). [PubMed] [Google Scholar]

4. Gupta KK, Singh A, Singh G, Aggarwal S. Uncommon drug abuse: an anaesthetist dilemma. Anesth Essays Res. 2015;9(1):116-7. [PubMed] [Google Scholar]

5. de Sousa HF, de Oliveira MF, Lima MD, De Oliveira JR. Mephentermine dependence without psychosis: a Brazilian case report. Addiction. 2010;105(6):1129-30. [PubMed] [Google Scholar]

6. Docherty JR. Pharmacology of stimulants prohibited by the World Anti-Doping Agency (WADA). Br J Pharmacol. 2008;154(3):606-22. [PubMed] [Google Scholar]

7. Oliveira MF, de Sousa HF, Lima MC, de Oliveira JR. Mephentermine: rediscovering its biology and use, misuse and their implications. Braz J Psychiatry. 2011;33(1):98-9. [PubMed] [Google Scholar] 